\title{
Physicochemical, Nutraceutical and Sensory Traits of Six Papaya (Carica papaya L.) Cultivars Grown in Greenhouse Conditions in the Mediterranean Climate
}

\author{
Vittorio Farina ${ }^{1, * \mathbb{C}}$, Ilenia Tinebra ${ }^{1}$, Anna Perrone $^{2}$, Giuseppe Sortino $^{1}{ }^{\mathbb{C}}$, Eristanna Palazzolo ${ }^{1}$, \\ Giuseppe Mannino $^{2}$ (D) and Carla Gentile ${ }^{2}$ (D) \\ 1 Department of Agricultural, Food and Forest Sciences (SAAF), Università degli Studi di Palermo, \\ Viale delle Scienze, 90128 Palermo, Italy; ilenia.tinebra@unipa.it (I.T.); giuseppe.sortino@unipa.it (G.S.); \\ eristanna.palazzolo@unipa.it (E.P.) \\ 2 Department of Biological, Chemical and Pharmaceutical Sciences and Technologies (STEBICEF), \\ Università degli Studi di Palermo, Viale delle Scienze, 90128 Palermo, Italy; anna.perrone@unipa.it (A.P.); \\ giuseppe.mannino@unipa.it (G.M.); carla.gentile@unipa.it (C.G.) \\ * Correspondence: vittorio.farina@unipa.it; Tel.: +39-09123896090
}

Received: 5 March 2020; Accepted: 31 March 2020; Published: 2 April 2020

\begin{abstract}
Six papaya (Carica papaya L.) cultivars, grown in a Mediterranean climate under greenhouse conditions, were screened for physicochemical properties, antioxidant capacity, nutritional and sensory characteristics. The fruits, harvested with more than $50 \%$ of yellow surface (between $60 \%$ and $77 \%$ ) were tested for carotenoids content, phenolic content, reducing activity (ABTS) and cellular antioxidant activity $\left(\mathrm{CAA}_{50}\right)$. The physicochemical traits were measured in terms of the titratable acidity and soluble content whereas proximal composition along with moisture, fats, total sugar, ash, vitamin A, C and E content. Moreover, the sensory profile was analyzed by a semi-trained panel. Although the six analyzed cultivars reached qualitative characteristics to satisfy market needs, significant differences among them were found in a genotype-dependent manner. In particular, Cartagena and Maradol cultivars evidenced the highest values of minerals and vitamins, carotenoids, polyphenols, ABTS and $\mathrm{CAA}_{50}$ and reached the best commercial requisites (size, total soluble solids content/titratable acidity ratio). As for sensory analysis, we observed significate differences only for sweetness, juiciness, odor and flavor of peach and exotic fruits whereas descriptors related to unpleasant defects or sensations always have very low scores in all the observed cultivars. These results highlight the possibility of obtaining quality papaya fruits in a Mediterranean climate using greenhouse growing.
\end{abstract}

Keywords: fruit quality; antioxidant activity; antiproliferative activity; carotenoids; physicochemical

\section{Introduction}

Papaya (Carica papaya L.) is a perennial herbaceous plant native to tropical America, with a range that extends from Asia, to America and Africa. Its diffusion is due to the abundance and longevity of its seeds. Papaya is a climacteric fruit whose maturation is accompanied by tissue softening, an exocarp color change and the development of a strong and characteristic aroma. The color varies according to the degree of ripeness: when the fruit is unripe, the exocarp is green; in advanced maturation, the exocarp becomes yellow-orange and the pulp becomes an intense orange. In recent years, there has been a constant demand for papaya, in part thanks to the change in consumers' lifestyles [1] and in continuous consumer interest towards fruits with high nutraceutical properties. The latest data available show that the worldwide production of papaya reached 12.5 million tonnes per year. India is 
the largest producer of papaya followed by Nigeria, Brazil, Mexico, and Indonesia [2,3]. In Europe, its cultivation is limited to a few Mediterranean countries, such as Spain and Italy where it is only cultivated in Sicily under greenhouses [1,4]. The greenhouse protects the plants from the frequent trade winds and the low temperatures of the winter season. In Sicily, varietal selection is performed to obtain plants with hermaphrodite flowers to promote self-pollination, and with small fruits [5]. However, the propagation of seeds that originated in tropical areas has caused the spread of numerous genetic entities that produce very heterogeneous products. This presence of very different selections leads to fruits being brought to market with widely different pomological features, aromas and flavors. This goes against market demand and makes it more difficult for consumers to appreciate the product. The visual appearance, which is often associated with the product's quality, is the first factor that influences the consumer to make a purchase, followed by physicochemical and nutraceutical characteristics when the product is consumed. Generally, pulp has a high sugar content, containing about $10 \mathrm{~g}$ of carbohydrates per $100 \mathrm{~g}$ of fresh pulp [6], is also rich in minerals such as potassium and magnesium, in vitamin B and is a good source of antioxidant phytocomponents. Moreover, it contains about $60 \mathrm{mg}$ of ascorbic acid, polyphenolic compounds and is one of the richest fruits in carotenoids [6]. The main carotenoids that have been identified are lycopene, $\beta$-criptoxanthin and $\beta$-carotene [7]. The fruit's size, shape, color, flesh firmness, content in soluble solids, and concentration of acids all indicate its ripeness. Considering the short shelf-life of fruits harvested at full ripeness, the harvest is generally carried out early when the exocarp color varies from dark green to light green and a yellow stripe appears at the base of the fruit.

The ripeness papaya scale of reference is that described by Basulto et al. [8]. According to this scale, the stages of harvesting are stage 3 (one or more orange- colored stripes in skin; pulp almost completely orange in color, except near skin, still hard but contains less latex) and 4 (skin clearly orange in color with some light green areas; pulp completely orange, except near peduncle, softer than in stage 3, but still too hard for consumption, low latex content).

It has been reported that the loss of chlorophyll produces yellow and red tones; carotenoids, lycopene and other pigments are responsible for these colors that will increase during ripening [9]. In Sicily, given the relative proximity of the European markets, the fruits could be harvested for consumption later and therefore allowed to ripen to late stages. This would improve the organoleptic characteristics of the fruits since, on-tree ripening is considered less drastic and usually associated with better quality parameters of fruit that ripens in storage. Papayas that remain attached to the tree will also delay ripening compared to papayas that ripen in storage $[9,10]$. Furthermore, ripening in storage at high temperatures and low relative humidity affects nutritional and organoleptic qualities [11]. On-tree ripened papayas that are harvested at late stages receive a constant supply of sucrose produced by the photosynthesis in the leaves. Although some fruits accumulate starch that breaks down into sugars through catabolic degradation during the ripening process, this is not the case for papayas [12]. Thus, papayas left on-tree until late stages will have an advantage over those harvested at early stages. It is important for the consumers that the flavor should be sweet, and the texture of the fruit should be firm [13]. During the sweetness process there are changes in the profiles and levels of phenolic compounds which contribute for the flavor [11], and also the disappearance of the latex, which is considered by consumers as bitter, is a characteristic of green papaya [14].

The aim of this study is to determine the physiochemical and nutraceutical characteristics of six papaya cultivars, obtained from seed, cultivated in Mediterranean climate in Sicily in greenhouse conditions and harvested at late stages.

\section{Materials and Methods}

\subsection{Plant Material}

The research was carried out in a commercial orchard in Palermo (33S 0333746 m.E, 4217131.00 m.N) on six different cultivars of hermaphrodite papaya plants, originating from seeds. The cultivars analyzed 
are: Guinea Gold (Australia), Sinta (Philippines), Honeydew (India), Cartagena (Dominican Republic), Maradol (Cuba) and Solo (Barbados). Trees (3 plants per cultivar) were subjected to routine orchard cultivation. The fruits were hand-picked at stage 4 , using the color of the skin fruit as maturity index [8]. They also allowed to develop naturally on-tree and later they were harvested during June-July 2016, when reached more than $50 \%$ of yellow surface (between $60 \%$ and $77 \%$ ). The fruit harvest took place on different dates, depending on maturation age, which is different for each cultivar. For each cultivar selected, 15 fruits were analyzed per tree, which were submitted to physicochemical and sensory analysis. Papayas were selected according to visual color perception, elongated shape, good physical condition, and lack of any signs of anthracnose or ring spot virus. Fruits were transported to the laboratory for evaluation under a controlled temperature $\left(20-25^{\circ} \mathrm{C}\right)$ and analyzed when papayas reached the consumption point $(95 \%-100 \%$ orange in the peel).

\subsection{Physicochemicals Analyses}

Fruit Weight (FW) was determined by a digital scale (Gibertini, Italia). For the color evaluation, each fruit was photographed with a digital camera and digital images were used to determine the percentage of yellow cover peel color. We used the F.A.S. (Fruit Analysis System) software, based on a MATHLAB 6.0 algorithm. Chroma $\left(C^{*}\right)$ and hue angle $\left(h^{\circ}\right)$ were determined using $a^{*}$ and $b^{*}$ values according to Equations (1) and (2).

$$
\begin{aligned}
& \mathrm{C}^{*}=\left(\mathrm{a}^{*} 2+\mathrm{b}^{*} 2\right)^{0.5} \\
& \mathrm{~h}^{\circ}=\arctan \left(\mathrm{b}^{*} / \mathrm{a}^{*}\right)
\end{aligned}
$$

Flesh Firmness (FF) was measured at the equator of the fruit using a digital penetrometer TR5325 (Turoni, Forlì, Italy). The puncture was performed with a cylindrical needle (8 $\mathrm{mm}$ diameter) and the firmness was expressed in Newtons (N).

The flesh juice was submitted to a chemical analysis. The pulp of each fruit was extracted using a centrifugal juicer (Ariete, Italy) to obtain a juice in order to evaluate Juiciness (J) per $100 \mathrm{~g}$. Therefore, Juice Soluble Solids Content (TSSC) was measured with an optical digital refractometer (Atago, Japan). Titratable Acidity (TA) was determined according to method 942.15 (AOAC, 1990). The sample was diluted 1:1 by weight of papaya pulp and distilled water using a homogenizer (Fisher Scientific PCR $125 \mathrm{FTH}-115$ ) for $1 \mathrm{~min}$, at medium speed. Subsequently, $10 \mathrm{~mL}$ of the above solution were titrated with $0.1 \mathrm{~N} \mathrm{NaOH}$ until the solution turned pink. TA results were expressed in $\mathrm{g}$ citric acid/100 $\mathrm{g}$ fresh fruit. We also determined the TSSC/TA ratio.

\subsection{Standards and Chemicals}

Ascorbic Acid (AA), [2,2-azinobis(3-ethylbenzothiazoline-6-sulfonic acid)] diammonium salt (ABTS), 2,2-azobis (2-methylpropionamidine) dihydrochloride (ABAP), 2,7-dichlorofluorescein diacetate (DCFHDA), Folin-Ciocalteau's reagent, Hanks' balanced salt solution (HBSS), 6-hydroxy-2,5,7,8-tetramethylchroman-2-carboxylic acid (Trolox), potassium persulfate, and phenolic standards (apigenin, benzoic acid, caffeic acid, cinnamic acid, p-coumaric acid, ferulic acid, gallic acid, phydroxybenzoic acid, luteolin, mangiferin, protocatechuic acid, syringic acid, vanillic acid, vanillin) were purchased from Sigma-Aldrich (Gillingham, UK). $\beta$-Carotene was obtained from Extrasynthese (Genay, France). Acetonitrile, acetone and methanol (LC-MS grade) were purchased from Biosolve B.V. (Valkenswaard, The Netherlands) and acetic and formic acid from VWR International B.V. (Roden, The Netherlands). RPMI, fetal bovine serum (FBS), phosphate buffered saline (PBS), L-glutamine solution (200 mM), trypsin-EDTA solution (170,000 U/L trypsin and 0.2 g/L EDTA) and penicillin-streptomycin solution $(10,000 \mathrm{U} / \mathrm{mL}$ penicillin and $10 \mathrm{mg} / \mathrm{mL}$ streptomycin) were purchased from Lonza (Verviers, Belgium). All other materials and solvents were of analytical grade unless indicated otherwise. 


\subsection{Preparation of Fruit Extracts}

The fruits were peeled and the pulp was finely chopped and weighted. Then, $5 \mathrm{~g}$ of flesh homogenate were extracted with $5 \mathrm{~mL}$ of ethanol for $30 \mathrm{~min}$ at room temperature while stirring. The extraction was repeated twice. After centrifugation and filtration on Whatman filter paper $0.45 \mu \mathrm{m}$, the supernatants were recovered, combined, aliquoted and stored at $-80^{\circ} \mathrm{C}$. The ethanol extracts were used for the determination of the radical scavenging and antioxidant activities, the total polyphenolic content and the antioxidant vitamin content.

\subsection{Total Carotenoids Content}

The Total Carotenoid content (TC) was evaluated spectrophotometrically, $5 \mathrm{~g}$ of homogenate pulp were extracted with $5 \mathrm{~mL}$ of ethyl acetate and mixed for $10 \mathrm{~min}$ at $4{ }^{\circ} \mathrm{C}$ and filtered through a Millex HV $0.45 \mu \mathrm{m}$ filter (Millipore, Billerica, MA). TC was calculated according to the method of De Ritter and Purcell using an extinction coefficient of $\beta$-carotene of 2.505 and was expressed as $\mu \mathrm{g} \beta$-carotene/g FW. All measurements were done in three replicates.

\subsection{Total Phenolic Content}

Total Phenolic content (TF) was determined by the reduction of Folin-Ciocalteu's reagent to blue pigments, in alkaline solution. For each extract, appropriately diluted in water, $500 \mu \mathrm{L}$ of the Folin-Ciocalteau reagent was added. After an incubation of $5 \mathrm{~min}, 2 \mathrm{~mL}$ of a $10 \% \mathrm{Na}_{2} \mathrm{CO}_{3}$ solution were added. The reaction mixture was later brought to $10 \mathrm{~mL}$ with distilled water and then incubated at room temperature for $90 \mathrm{~min}$. At the end of the incubation period, the absorbance at $740 \mathrm{~nm}$ of the reaction mixture was recorded using an incubation mixture that contained ethanol. Quantitation was carried out by reference to a curve constructed with GA, and the results were expressed as mg GA equivalents (GAE) per $100 \mathrm{~g}$ FW. All measurements were performed in three replicates.

\subsection{Total Antioxidant Activity}

The antioxidant activity was evaluated using the ABTS radical cation decolorization assay prepared by oxidation of the ABTS salt with potassium persulphate $\left(\mathrm{K}_{2} \mathrm{~S}_{2} \mathrm{O}_{8}\right)$ [15]. The synthetic antioxidant Trolox was used as the standard, and the results were expressed as $\mu \mathrm{mol}$ of equivalent Trolox (TE)/100 g FW.

\subsection{Radical Scavenging Activity (CAA)}

The antioxidant activity of the ethanol extracts was evaluated in a cellular system using the Cellular Antioxidant Activity assay (CAA) [16]. The assay was carried out as previously described [17,18].

\subsection{Proximate Composition}

The ascorbic acid (Vitamin C) and the retinol (Vitamin A) were determined according to procedures previously described by Barros et al. [19]. For this determination the dried methanolic extract $(100 \mathrm{mg})$ was extracted with $10 \mathrm{~mL}$ of $1 \%$ metaphosphoric acid for $45 \mathrm{~min}$ at room temperature and filtered through Whatman No. 4 filter paper. The filtrate $(1 \mathrm{~mL})$ was mixed with $9 \mathrm{~mL}$ of 2.6-dichlorophenolindophenol and the absorbance was measured within $30 \mathrm{~min}$ at $515 \mathrm{~nm}$ against a blank. Vitamin C and Vitamin A was calculated on the basis of the calibration curve of authentic L-ascorbic acid $(0.02-0.12 \mathrm{mg} / 100 \mathrm{~g})$. The vitamin $\mathrm{E}$ was determined by HPLC after extraction of the lipophilic component from pulp samples. All measurements were done in three replicates.

Ash content was determined through the procedure described in AOAC [20,21] while the Kjeldahl method was used for protein determination. The fat content (FAT) was obtained through acid hydrolysis with a $1: 4 \mathrm{HCl}$ solution on the sample followed by filtration and dehydration in a heater $\left(70{ }^{\circ} \mathrm{C}\right)$. After solvent evaporation, the extraction in Soxhlet with petroleum ether was determined through a gravimetric method of residual fat. The carbohydrate content (TSG), either free or present in 
polysaccharides, was obtained with the anthrone method reported in Loews (1952). Carbohydrates were first hydrolyzed into simple sugars using dilute hydrochloric acid. In hot acidic medium, glucose is dehydrated to hydroxymethyl furfural that with anthrone forms a green-colored product with an absorption maximum at $630 \mathrm{~nm}$ [21]. The contents of $\mathrm{Ca}, \mathrm{Mg}, \mathrm{K}, \mathrm{Na}, \mathrm{P}$, Fe were determined using atomic absorption spectroscopy following wet mineralization while $\mathrm{P}$ was determined using a colorimetric method [22].

\subsection{Sensory Profile}

Fruits were tested to evaluate the organoleptic characteristics through semi-trained panel tests. The sensory profile was defined by a panel of nine judges with extensive experience in the sensory evaluation of several kinds of fruits [23-25]. The judges in a preliminary meeting, generated twenty-one attributes on the basis of frequency of citation ( $>60 \%)$ : Peel Color (PC), Flesh Color (FC), Presence of Filaments (FIL), Consistency (CN), Sea Odor (SO), Peach Odor (PO), Exotic Odor (EXO), Medicinal Odor (MO), Cheese Flavor (CF), Burnt Oil Flavor (BO), Acid (AC), Sweet (SW), Bitter (BT), Juiciness (JUI), Floweriness (FL), Seafood Flavor (SFL), Peach Flavor (PF), Taste of Exotic Fruits (EXF), Medicine Flavor (MF), Taste of Cheese (CHF), Aroma of Burnt Oil (BF). A discontinuous scale (value 1.0 absence of the sensation; value 9.0 highest intensity) was utilized for evaluation. The order of presentation of the fruits was randomized for each participant, and water was provided for rinsing the mouth between the different papaya samples.

\subsection{Statistical Analysis}

All data were tested for differences between the genotype's selection using the one-way analysis of variance (ANOVA; general linear model) followed by Tukey's multiple range test for $p \leq 0.05$.

\section{Results and Discussion}

\subsection{Physiochemical Analyses}

The examined papaya cultivars (cv) showed a great variability in pomological traits. FW varied from $384.40 \mathrm{~g}$ to $1194.50 \mathrm{~g}$ (Figure 1a). Similar results were found in four different varieties of papaya grown in Bangladesh [26]. Papayas are classified according to Size Codes A-J [13], ranging in average weight from 200-300 g (Size A) to over $2000 \mathrm{~g}$ (Size J).

This Standard applies to fruits of commercial varieties of papayas to be supplied fresh to the consumer, after preparation and packaging [27]. According to this classification, the Guinea Gold cv have size code H, Sinta cv have size code B, Honeydew and Solo cv have size code E, and Cartagena and Maradol cv have size code G. The main varieties on the European market are Solo Sunrise and Golden for small fruits up to $700 \mathrm{~g}$, and Formosa for large fruits above $1 \mathrm{~kg}$. Consumers tend to prefer smaller papayas, particularly in northwestern Europe, because they suit individual consumption better [13].

FF shows values between 0.20 and $2.40 \mathrm{~kg} / \mathrm{cm}^{2}$ (Figure $1 \mathrm{~b}$ ). Solo $\mathrm{cv}$ was the firmest fruit followed by Sinta and Honeydew cv while Guinea Gold, Cartagena and Maradol cv had values below $1 \mathrm{~kg} / \mathrm{cm}^{2}$. Our results are compatible with those observed by Basulto et al., [8], which recorded values ranging from $2 \mathrm{~kg} / \mathrm{cm}^{2}$ for the fruits of stages 3 and 4 (fruits colored orange yellow from a few strips to the entire surface) and $1 \mathrm{~kg} / \mathrm{cm}^{2}$ for the fruits of stages 5 and 6 (fruits completely colored).

Blankenship and Unrath [28], observed decreases in firmness before any increase in internal ethylene concentration during apple ripening. Paull [11], proposed that ethylene only speeds or coordinates the firmness changes during soursop ripening, where increases in production only occurred at more advanced stages of ripening. The ripening process, including firmness loss, can be the result of an increase in ethylene sensitivity of the fruit tissue and not necessarily dependent on increases in ethylene production. Moreover, a low quantity of this hormone can be sufficient for beginning the ripening process. Flores et al. [29], concluded that melon softening only partially depends on 
ethylene, since firmness loss of selection that express the antisense 1-aminocyclopropane-1-carboxylic acid oxidase was about $50 \%$ lower than in normal fruit. Therefore, it is reasonable to assume that other ethylene-independent processes are involved in fruit ripening. In fact, firmness loss has a close relationship with the activity of pectic enzymes, which are related to ethylene but at different dependence levels [30].
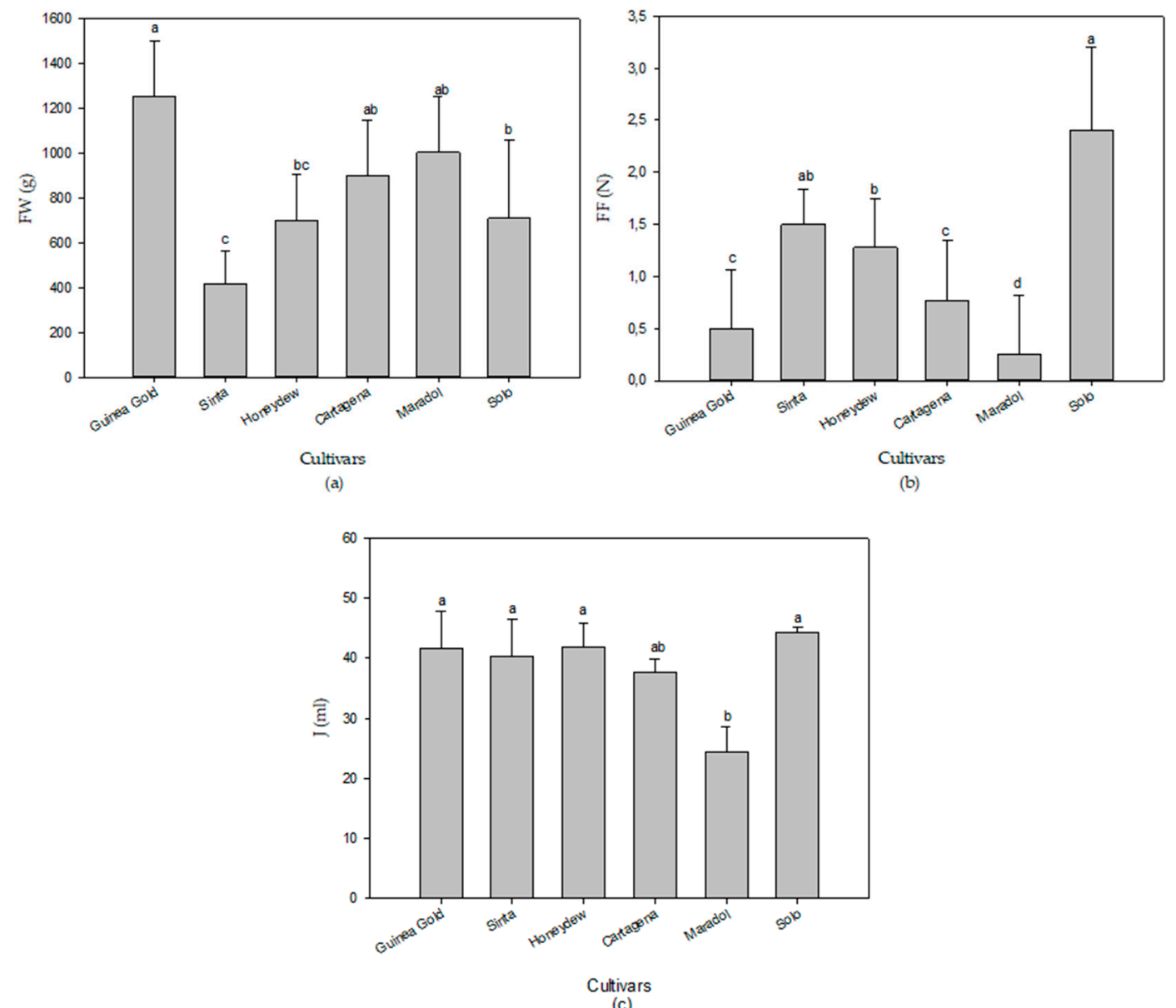

(c)

Figure 1. Pomological traits of the 6 papaya cultivars. (a) FW = Fruit Weight (g); (b) FF = Flesh Firmness $\left(\mathrm{kg} / \mathrm{cm}^{2}\right) ;(\mathrm{c}) \mathrm{J}=$ Juiciness $(\mathrm{ml} / 100 \mathrm{~g})$. Values represented as mean $\pm \mathrm{SD}$. For each column, within the same series different letters indicate significantly different at $p \leq 0.05$ as measured by Tukey's multiple range test. Letter " $a$ " denotes the highest value.

Finally, in studies conducted on Maradol and Golden papaya, there were no differences in pulp firmness by maturity stage, meaning that this variable is a reliable quality standard for Maradol papaya [8]. Firmness in Maradol continued to decrease, albeit at a lower rate, after the ethylene peak, when orange-yellow skin color begins to develop. In Golden papaya, by contrast, ethylene production does not peak until fruit reaches edible pulp firmness and quality changes have already occurred [31].

For the majority of fruits, juiciness is a principal texture attribute. Few, if any, foods can match most fruit for the intensity of this attribute [32]. Juiciness, in all cultivars of papaya, showed a rather homogeneous behavior with less marked differences between the different $\mathrm{cv}$. The obtained values ranged between 22.10 and $41.80 \mathrm{~mL} / 100 \mathrm{~g}$ (Figure 1c). The results show that the fruits of Cartagena and Maradol cv have a low juiciness, with significant differences within the Guinea Gold, Sinta, Honeydew and Solo cv. This shows that these selections can be more appreciated by consumers due to their higher juiciness.

The color value obtained from the study for $\mathrm{L}^{*}, \mathrm{a}^{*}, \mathrm{~b}^{*}$ values were recorded as in Figure 2. 
Color is one of the most important attributes of agri-food products, since consumers associate it with freshness and it is critical in the acceptance of a product [33]. Producers strive to prevent products with defective colorations from reaching the market, as well as ensuring that individual products are packed in batches with a similar color [34]. Fruit color is the most obvious change in many fruits during ripening, and often is the major criterion used by consumers to determine whether the fruit is ripe or unripe.

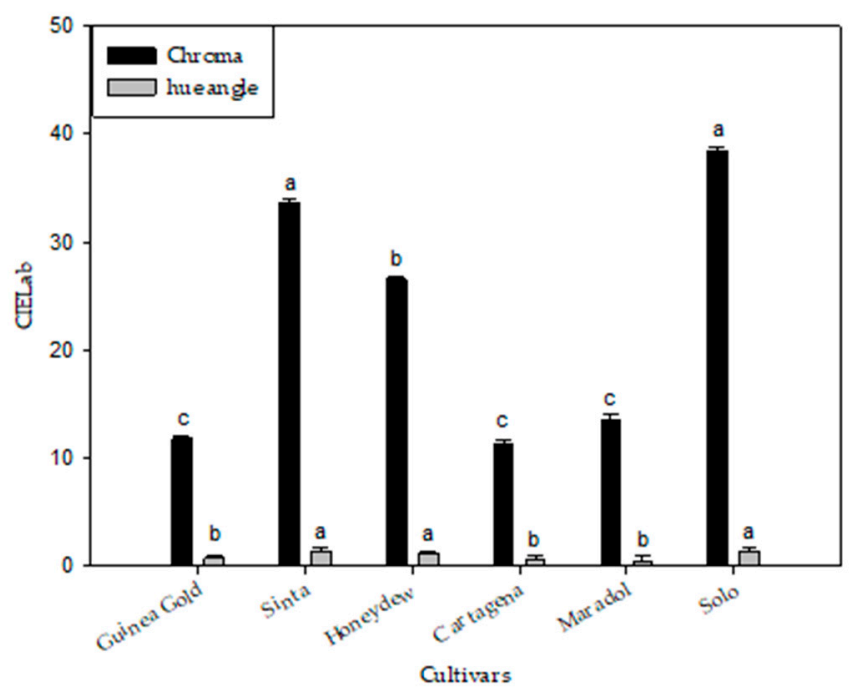

Figure 2. Chroma and hue angle of the six papaya cultivars. Values represented as mean $\pm \mathrm{SD}$. For each column, within the same series different letters indicate significantly different at $p \leq 0.05$ as measured by Tukey's multiple range test. Letter "a" denotes the highest value.

The Chroma values obtained from the results analysis for the 6 cultivars are comparable with those reported by Fuggate et al. [10] and Gayosso-García et al. [35]. The highest values were obtained for the Sinta and Solo cv. Considering that as reported by Schweiggert et al. [9] during ripening in the field, the Chroma of papaya peel increased, as the colors change from green to red, the values obtained for the 6 papaya cultivars are in agreement with this. The lower Chroma values we find for the Cartagena and Maradol cultivars seem to be due to the fact that these had less color saturation due to the opacity present [36]. The hue angle $\left(\mathrm{h}^{\circ}\right)$ has low values, almost similar in all cultivars $(p \leq 0.05)$. Considering that the hue allowed to appreciate a precise differentiation between physiological maturity, ripeness for consumption and overripe fruit [36], six cv of papaya had a low hue value as they are at the state of consumption ripeness [8,37]. From what can be seen from the results is that the fruits show excellent color saturation. According to Fuggate et al. [10] which describes that on-tree ripened fruit peel revealed a clear progression to orange-red color as shown in flourishing $\mathrm{a}^{*}$ values. This indicates that biosynthesis of red color pigments (carotenoids) in the fruit peel occurred during on-tree fruit development, and may require some intermediates from the stem and/or from environmental factors such as sun light.

Papaya has a low starch content (around $0.5 \%-1 \%$ ), therefore, the fruit does not have significant amounts of starch to be hydrolyzed during ripening, which results in little, if any, change in soluble contents during the postharvest period. According to Zhou and Paull [38], sucrose content increases up to five times at 110-130 days after anthesis in papayas attached to the tree, when skin color begins to change. Papaya sugar content remains constant during postharvest ripening, suggesting that sugar accumulation in pulp is related to continued sugar translocation from plant to fruit.

TSSC of the six cultivars varied from 9.20 to $10.70{ }^{\circ}$ Brix (Figure 3a). Fruit of Sinta and Honeydew $\mathrm{cv}$ showed the highest value, while the lowest was recorded in Cartagena cv. These results are lower than observed by Basulto et al. [8] in a tropical environment where values are around $12{ }^{\circ}$ Brix for the 
fruits of stages 5 and 6 (orange-colored fruit). These differences could be due to the lower temperatures of our environments [39].

TA has shown, even in this case, a similar behavior between the different examined cultivars (Figure 3b). Solo cv showed the highest values followed by Guinea Gold cv, Sinta and Honeydew cv whereas Cartagena and Maradol cv are the lowest ones. These values are higher than those reported in the literature for Solo varieties and for two Local varieties analyzed in Bangladesh [40]. Even in this case, these differences could be due to the temperatures [39]. In addition, Lazan et al. [41], concluded that the treatable acidity increases with fruit ripening until approximately $75 \%$ of the skin is yellow, decreasing thereafter.

All cultivars showed a similar behavior for the TSSC/TA ratio, but Cartagena and Maradol cv reached the high value.

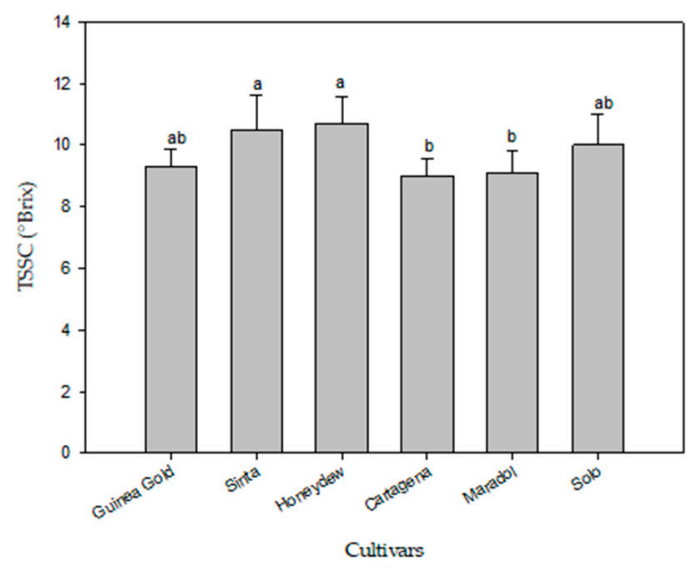

(a)

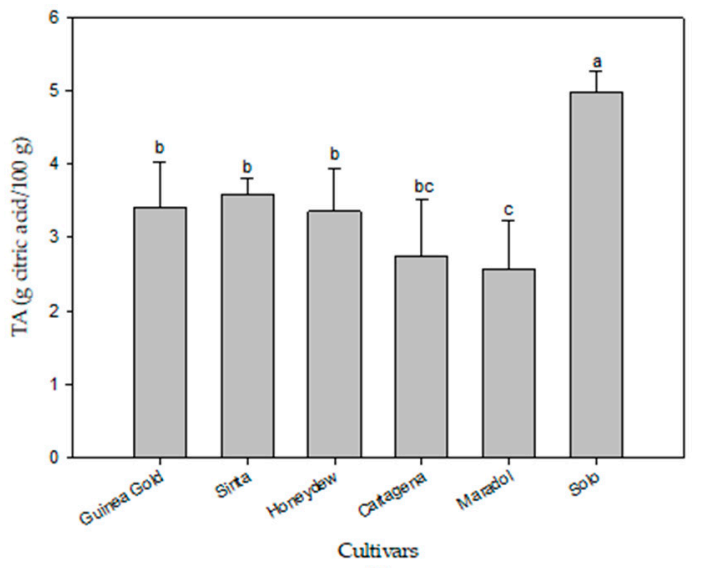

(b)

Figure 3. (a) Juice Soluble Solids Content (TSSC) of the 6-papaya cultivars; (b) Titratable Acidity (TA) of the 6-papaya cultivars. Values represented as mean \pm SD. For each column, within the same series different letters indicate significantly different at $p \leq 0.05$ as measured by Tukey's multiple range test. Letter " $a$ " denotes the highest value.

By using linear regression, a model was generated to enable TSSC content predicted from the color value obtained from the colorimeter. The TSSC content acted as a dependent variable while color acted as an independent variable. The correlation with TSSC and Chroma was established with $\mathrm{R}^{2}=0.3507$, similar results were obtained from Barragán-Iglesias et al. [36], therefore TSSC showed a nonlinear relationship with color.

\subsection{Phytochemical Profile and Antioxidant Properties}

The Total Carotenoid content (TC) is within a wide concentration range varying from 142.25 to $4134.26 \mu \mathrm{g} \beta$-carotene/g FW (Figure 4).

Carotenoids play a very important role in human health and nutrition, recognized as strong antioxidants due to their ability to trap singlet oxygen and eliminate the peroxyl radical [42]. Various in vitro and in vivo studies have shown that carotenoids prevent cardiovascular diseases and impact cell signaling pathways [42], in addition to providing protection against some types of cancer [43].

Among the cultivars analyzed, Cartagena and Maradol cv have the highest carotenoid value. The carotenoid content seems to be correlated with that of the FF. Guinea Gold, Cartagena and Maradol $\mathrm{cv}$, with a pulp consistency of less than $1 \mathrm{~kg} / \mathrm{cm}^{2}$, have the highest carotenoid values. Sinta, Honeydew and Solo cv, with the highest consistency values, have very low carotenoid values. This fact suggests a relationship with a relatively more advanced degree of maturation but when comparing the carotenoid content with the percentage of color of the skin, no obvious correlation can be observed. 


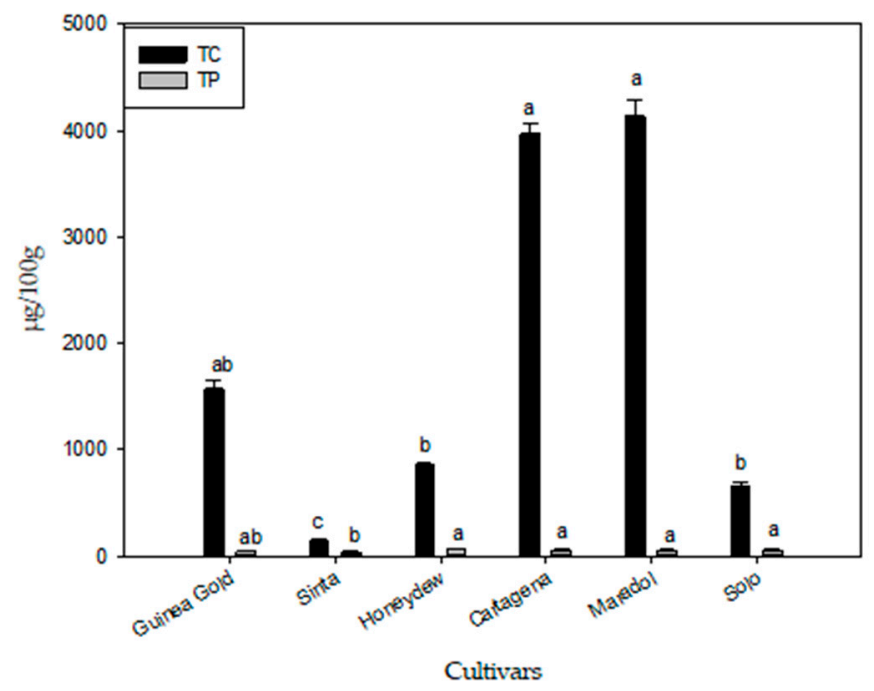

Figure 4. Phytochemical profile of the 6 papaya cultivars. Total Carotenoid content (TC) ( $\mu \mathrm{g} / \mathrm{g}$ FW); Total Phenolic content (TP) (GAE/100 g). Values represented as mean \pm SD. For each column, within the same series different letters indicate significantly different at $p \leq 0.05$ as measured by Tukey's multiple range test. Letter " $a$ " denotes the highest value.

The high variability of the total carotenoid content could be justified by a high genotype-based diversification of carotenoid synthesis. In the literature, in particularly colored tropical fruits such as papaya, lycopene, $\beta$-cryptoxanthin and $\beta$-carotene are the main identified carotenoids [35]. The fruits analyzed in this study have a comparable carotenoid content and, for some selection, higher than that reported in the literature for other papaya fruits [44].

Phenols contribute to fruits' color and taste and have been described as possessing anticarcinogenic and antimutagenic activity [45]. Various studies have shown that phenolic compounds have high antioxidant potential, resulting in a beneficial effect to human health [43]. The total polyphenolic content (TP) of the six papaya cultivars studied varies between 38.60 and $60.20 \mathrm{mg}$ GAE/100 $\mathrm{g}$ FW, with an average value of $50.79 \pm 11.12 \mathrm{mg} \mathrm{GAE} / 100 \mathrm{~g}$ FW. From the results obtained, it can be seen that the average value determined for the TP is comparable to that reported in the literature for other hydrophilic extracts of papaya fruits [46].

The accumulation of phenolic compounds varies greatly in relation to the physiological state of the fruit and results from the balance between biosynthesis and further metabolic phases, such as turnover and catabolism [46]. In addition, a decreasing trend in total phenol content and antioxidant capacity on Maradol papaya skin and pulp was reported during maturation [35]. The values obtained are comparable to those reported for the pulp of other tropical and subtropical fruits with documented positive properties for health [47].

The radical-scavenging and reducing activity of the fruits of the six analyzed cultivars was measured by evaluating the ability to decolorate in a solution of the ABTS radical. The values of radical scavenging activity, assessed by the ABTS test, are included in the range $60.00 \pm 10.00-289.60 \pm$ $9.55 \mu \mathrm{mol} \mathrm{TE} / 100 \mathrm{~g}$ FW (Figure 5).

The fruits of Solo $\mathrm{cv}$ are those that exhibit the highest reducing activity values, followed by the fruits of Guinea Gold, Cartagena, and Maradol cv. The fruits of Sinta and Honeydew cv have low values.

The results of the CAA assay (Table 1), used to assess the antioxidant activity of the ethanol extracts [46], was an average of $15.96 \mathrm{mg} F W / \mathrm{mL}$. The highest activity was recorded for the fruits of Maradol cv while the lowest was recorded for the fruits of Honeydew cv. Cellular antioxidant activity is not positively correlated with the TP and with the radical-scavenging activity. These results suggest qualitative differences in the phytochemical profile of the fruits of the studied cultivars. 


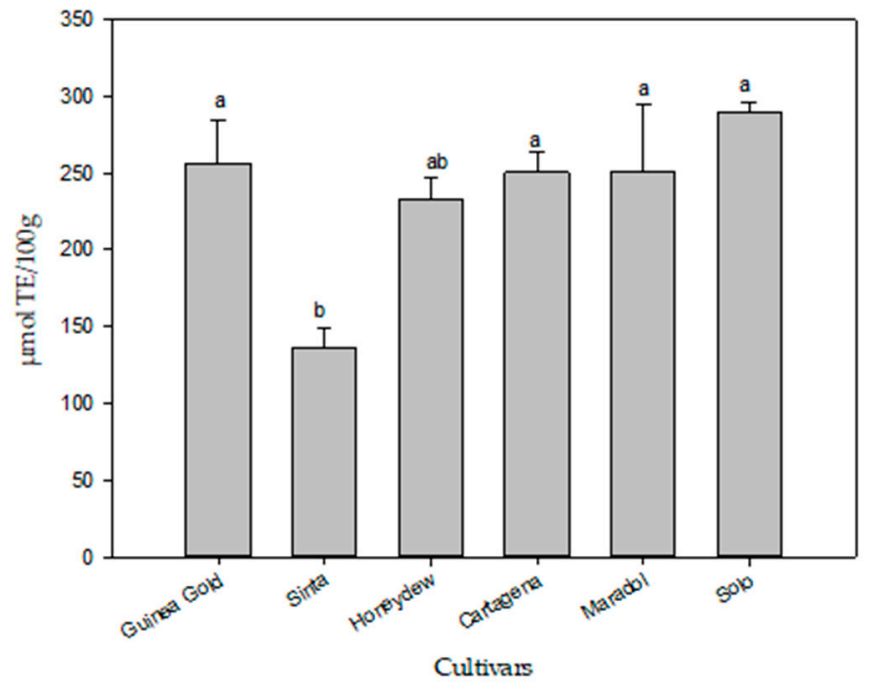

Figure 5. Antioxidant properties of the 6 papaya cultivars. Values represented as mean \pm SD. For each column, within the same series different letters indicate significantly different at $p \leq 0.05$ as measured by Tukey's multiple range test. Letter "a" denotes the highest value.

Table 1. Cellular Antioxidant Activity Assay $\left(\mathrm{CAA}_{50}\right)$ of the 6 papaya genotype selections. Values represented as mean $\pm \mathrm{SD}$. For each column, within the same series different letters indicate significantly different at $p \leq 0.05$ as measured by Tukey's multiple range test. Letter "a" denotes the highest value.

\begin{tabular}{cccc}
\hline Genotype & \multicolumn{3}{c}{ CAA $_{\mathbf{5 0}}$} \\
\hline Guinea Gold & 18.75 & \pm 0.18 & $\mathrm{~b}$ \\
Sinta & 15.09 & \pm 0.13 & $\mathrm{c}$ \\
Honeydew & 26.70 & \pm 0.43 & $\mathrm{a}$ \\
Cartagena & 14.03 & \pm 0.13 & $\mathrm{~d}$ \\
Maradol & 6.34 & \pm 0.05 & $\mathrm{e}$ \\
Solo & 14.89 & \pm 0.18 & $\mathrm{dc}$ \\
\hline
\end{tabular}

\subsection{Proximate Composition}

The activity of many important vitamins, such as vitamin A, C, E, or minerals, is notoriously included in the antioxidant properties of many fresh and raw foods, such as fruits or vegetables. Collectively, vitamins and other nature-derived molecules are known as "phytonutrients" [48].

The role of vitamin A is not restricted to their antioxidant properties. It is fundamental in signaling with retinol-binding protein to regulate insulin sensitivity and fat homeostasis [49,50]. In addition, vitamin A and related retinoids have therapeutic potential as immune modulators and the retinol is an important electron carrier in redox signaling [51] because it controls oxidative phosphorylation in mitochondria [52].

Vitamin A has values that are distributed in a range from 18.50 to $56.50 \mathrm{mg} / 100 \mathrm{~g}$, with an average value of $42.70 \mathrm{mg} / 100 \mathrm{~g}$ (Table 2). The cultivars with the highest vitamin A content are in Guinea Gold, Honeydew and Maradol, the lowest content is found in Sinta and Solo cv. Similar data was found for Solo variety papaya fruits, harvested at commercial maturity grown in Hawaii [53]. Depending on cultivar and ripeness, consuming about one-half of a papaya fruit (100 g) would provide between $2 \%$ and $10 \%$ of the need for vitamin A for the average adult. The USDA Nutrient Database (2004) lists $47 \mathrm{mg}$ RAE/100 $\mathrm{g}$ for papaya vitamin A content [54].

Vitamin $\mathrm{C}$ is a fundamental dietary supplement; it modifies some responses of the white adipose tissue towards oxidative stress, inhibits the secretion of leptin from adipocytes and is associated with a reduced risk of chronic diseases [55]. 
The vitamin C content of our extracts is within a range of concentration from 30.50 to $62.50 \mathrm{mg} / 100 \mathrm{~g}$, with an average value of $49.14 \mathrm{mg} / 100 \mathrm{~g}$ (Table 2). The lowest values have been registered for the fruits of Sinta and Solo cv, followed by the fruits of Honeydew cv. Guinea Gold, Cartagena, Maradol and Solo cv have a vitamin C content that is about 1.5 times larger than that recorded for other cultivars. The vitamin $C$ content recorded for our cultivars is comparable to that determined in fruits of other varieties of papaya [44]. The values obtained confirm that papaya is a fruit particularly that is rich in vitamin $C$ with a content comparable to that reported for citrus fruits.

The Vitamin E content is not significant for all six cultivars, according to USDA Nutrient Database [54] (Table 2).

Table 2. Vitaminic composition of the 6 papaya genotype selections. (a) Retinol (VIT. A mg/100 g); (b) Ascorbic Acid (VIT. C mg/100 g); (c) Tocopherol (VIT. E mg/100 g). Values represented as mean \pm SD. For each column, within the same series different letters indicate significantly different at $p \leq 0.05$ as measured by Tukey's multiple range test. Letter "a" denotes the highest value, "ns" denotes no significant.

\begin{tabular}{cccccccccc}
\hline Genotype & & Vit. A & & & Vit. C & & \multicolumn{3}{c}{ Vit. E } \\
\hline Guinea Gold & 56.50 & \pm 0.01 & $\mathrm{a}$ & 62.50 & \pm 0.01 & $\mathrm{a}$ & 0.29 & \pm 0.01 & $\mathrm{~ns}$ \\
Sinta & 18.50 & \pm 0.02 & $\mathrm{~d}$ & 31.50 & \pm 0.01 & $\mathrm{~b}$ & 0.17 & \pm 0.02 & $\mathrm{~ns}$ \\
Honeydew & 54.30 & \pm 0.01 & $\mathrm{a}$ & 56.70 & \pm 0.02 & $\mathrm{a}$ & 0.27 & \pm 0.02 & $\mathrm{~ns}$ \\
Cartagena & 48.50 & \pm 0.01 & $\mathrm{~b}$ & 59.00 & \pm 0.01 & $\mathrm{a}$ & 0.24 & \pm 0.03 & $\mathrm{~ns}$ \\
Maradol & 52.00 & \pm 0.03 & $\mathrm{a}$ & 60.50 & \pm 0.05 & $\mathrm{a}$ & 0.22 & \pm 0.01 & $\mathrm{~ns}$ \\
$\quad$ Solo & 26.50 & \pm 0.02 & $\mathrm{c}$ & 30.50 & \pm 0.01 & $\mathrm{~b}$ & 0.15 & \pm 0.04 & $\mathrm{~ns}$ \\
\hline
\end{tabular}

The flesh mineral content is presented in Table 3. All selections showed significant moisture, on average 73.54\%. Guinea Gold, Honeydew, Cartagena and Maradol cv had the highest MST values. High humidity levels were also found in papaya fruits from the Mbezi area in Dar es Salaam, Nigeria [56] and India [26].

The moisture level in a fruit is an important factor as it may affect its consistency and overall acceptability [57].

FAT did not show significant differences among cultivars and the average value is $0.38 \mathrm{~g} / 100 \mathrm{~g}$. The FAT content of Sicily papaya was higher than values reported for Nigerian papaya [58]. Considering that higher levels of FAT in these fruits indicate that they are not good sources of energy [54], Sicily papaya is better in this respect.

TSG ranged from 8.23 to $2.71 \mathrm{~g} / 100 \mathrm{~g}$, according to the available USDA ratio [54].

An average ASH content of $0.45 \mathrm{~g} / 100 \mathrm{~g}$ was observed. Low ASH content in the pulp indicates that the total inorganic mineral content is low. However, the moisture content is also low, showing that the pulp can be stored for a period of time without spoilage and it will not be susceptible to microbial growth [58].

Table 3. Flesh composition of the 6 papaya cultivars. (a) Moisture (MST \%); (b) Fats (FAT g/100 g); (c) Total Sugar (TSG g/100 g); (d) Ash (ASH g/100 g). Values represented as mean \pm SD. For each column, within the same series different letters indicate significantly different at $p \leq 0.05$ as measured by Tukey's multiple range test. Letter "a" denotes the highest value, "ns" denotes no significant.

\begin{tabular}{ccccccccccccc}
\hline Genotype & & MST & & \multicolumn{3}{c}{ FAT } & & \multicolumn{3}{c}{ TSG } & & ASH \\
\hline Guinea Gold & 88.23 & \pm 0.02 & $\mathrm{a}$ & 0.34 & \pm 0.05 & $\mathrm{~b}$ & 6.19 & \pm 1.60 & $\mathrm{~b}$ & 0.59 & \pm 0.03 & $\mathrm{a}$ \\
Sinta & 88.93 & \pm 0.06 & $\mathrm{a}$ & 0.34 & \pm 0.04 & $\mathrm{~b}$ & 6.55 & \pm 1.58 & $\mathrm{~b}$ & 0.57 & \pm 0.03 & $\mathrm{a}$ \\
Honeydew & 86.41 & \pm 0.63 & $\mathrm{c}$ & 0.23 & \pm 0.05 & $\mathrm{c}$ & 4.60 & \pm 1.68 & $\mathrm{c}$ & 0.59 & \pm 0.08 & $\mathrm{a}$ \\
Cartagena & 88.00 & \pm 1.02 & $\mathrm{a}$ & 0.33 & \pm 0.05 & $\mathrm{~b}$ & 7.02 & \pm 1.60 & $\mathrm{a}$ & 0.48 & \pm 0.12 & $\mathrm{~b}$ \\
Maradol & 87.46 & \pm 1.73 & $\mathrm{~b}$ & 0.34 & \pm 0.04 & $\mathrm{~b}$ & 7.35 & \pm 1.70 & $\mathrm{a}$ & 0.43 & \pm 0.10 & $\mathrm{~b}$ \\
Solo & 87.00 & \pm 1.20 & $\mathrm{~b}$ & 0.40 & \pm 0.02 & $\mathrm{a}$ & 7.02 & \pm 1.50 & $\mathrm{a}$ & 0.48 & \pm 0.10 & $\mathrm{~b}$ \\
\hline
\end{tabular}

In the mineral composition of the pulp (Table 4 ), $\mathrm{K}$ is the predominant mineral element of the papaya fruit. For other mineral elements, Cartagena cv showed the highest values. This data is 
similar to those reported in other recent studies on tropical fruits [59]. Calcium and potassium show slightly higher results than USDA Nutrition Database, while sodium shows slightly lower values [54]. Potassium, calcium and magnesium, are nutritionally important. The high concentration of these minerals could be an advantage; it has important roles in the maintenance of normal glucose-tolerance and in the release of insulin from beta cells of Langerhans islets [59].

Table 4. Mineral composition of the 6 papaya cultivars. Macroelements: (a) Calcium (Ca); (b) Magnesium (Mg); (c) Potassium (K); (d) Sodium (Na); (e) Phosphorus (P). Mean values (mg/100 g dry weight). Microelements: Iron $(\mathrm{Fe})$. Values represented as mean $\pm \mathrm{SD}$. For each column, within the same series different letters indicate significantly different at $p \leq 0.05$ as measured by Tukey's multiple range test. Letter "a" denotes the highest value, "ns" denotes no significant.

\begin{tabular}{ccccccc}
\hline Genotype & $\mathbf{C a}$ & $\mathbf{M g}$ & $\mathbf{K}$ & $\mathbf{N a}$ & $\mathbf{P}$ & $\mathbf{F e}$ \\
\hline Guinea Gold & $32.50 \pm 0.13 \mathrm{~b}$ & $18.00 \pm 0.03 \mathrm{~ns}$ & $172.50 \pm 0.22 \mathrm{~b}$ & $4.85 \pm 0.19 \mathrm{ab}$ & $36.00 \pm 0.04 \mathrm{a}$ & $0.84 \pm 0.15 \mathrm{a}$ \\
\hline Sinta & $47.00 \pm 0.08 \mathrm{a}$ & $17.00 \pm 0.01 \mathrm{~ns}$ & $222.00 \pm 0.13 \mathrm{a}$ & $5.00 \pm 0.13 \mathrm{ab}$ & $27.00 \pm 0.09 \mathrm{c}$ & $0.65 \pm 0.11 \mathrm{~b}$ \\
\hline Honeydew & $35.33 \pm 0.30 \mathrm{~b}$ & $16.00 \pm 0.05 \mathrm{~ns}$ & $164.67 \pm 0.17 \mathrm{~b}$ & $3.70 \pm 0.43 \mathrm{c}$ & $30.67 \pm 0.92 \mathrm{~b}$ & $0.33 \pm 0.08 \mathrm{c}$ \\
\hline Cartagena & $49.50 \pm 0.11 \mathrm{a}$ & $17.00 \pm 0.05 \mathrm{~ns}$ & $215.50 \pm 0.32 \mathrm{a}$ & $5.95 \pm 0.06 \mathrm{a}$ & $29.00 \pm 0.04 \mathrm{~b}$ & $0.70 \pm 0.20 \mathrm{~b}$ \\
\hline Maradol & $32.00 \pm 0.23 \mathrm{~b}$ & $15.00 \pm 0.04 \mathrm{~ns}$ & $198.00 \pm 0.09 \mathrm{ab}$ & $4.30 \pm 0.29 \mathrm{~b}$ & $26.00 \pm 0.06 \mathrm{c}$ & $0.28 \pm 0.02 \mathrm{c}$ \\
\hline Solo & $32.00 \pm 0.25 \mathrm{~b}$ & $15.00 \pm 0.06 \mathrm{~ns}$ & $198.00 \pm 0.27 \mathrm{ab}$ & $4.00 \pm 0.15 \mathrm{~b}$ & $26.00 \pm 0.12 \mathrm{c}$ & $0.28 \pm 0.14 \mathrm{c}$ \\
\hline
\end{tabular}

\subsection{Sensory Analysis}

Regarding sensory analysis, only CN, EXO, SFL, PF and EXF descriptors show significant differences between the cultivars (Figure 6).

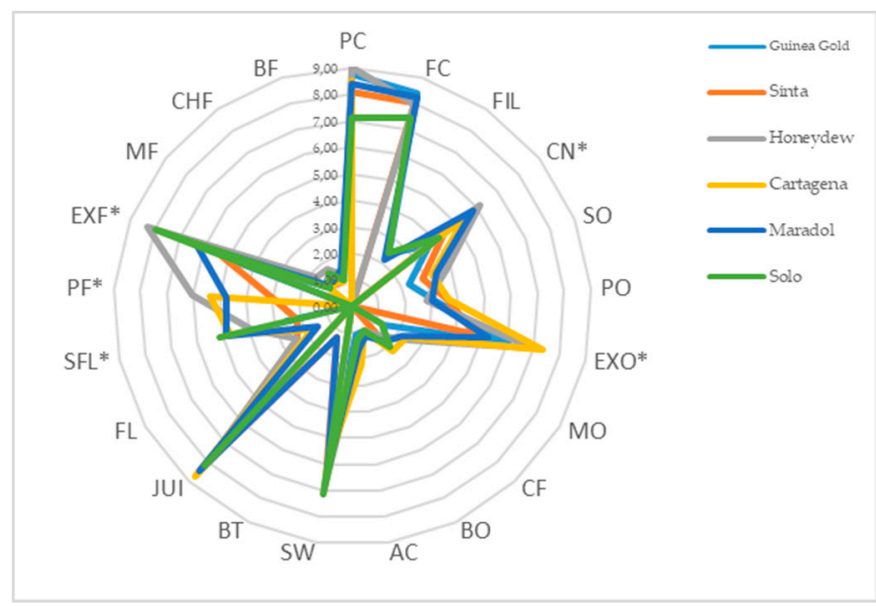

Figure 6. Sensory profile of the six papaya cultivars as evaluated by a trained panel. Values represented as mean \pm SD. Peel Color (PC); Flesh Color (FC); Presence of Filaments (FIL); Consistency (CN); Sea Odor (SO); Peach Odor (PO); Exotic Odor (EXO); Medicinal Odor (MO); Cheese Flavor (CF); Burnt Oil Flavor (BO); Acidity (AC); Sweetness (SW); Bitterness (BT); Juiciness (JUI); Flouriness (FL); Seafood Flavor (SFL); Peach Flavor (PF); Exotic Fruit Flavor (EXF); Medicinal Flavor (MF); Cheese Flavor (CHF); Burnt Oil Flavor (BF). For each descriptor the values marked with * indicate significant differences between cultivars $(p \leq 0.05)$.

The "Consistency" parameter has values in the range of 3.7 to 5.8. The data related to the "Exotic Odor" shows higher values for Cartagena cv, and the values are between 4.8 and 7.3. There are no significant differences for the negative descriptors except for the "Sea Flavor" parameter, which divides the fruits into two groups: better fruits belonging to Honeydew, Cartagena, Maradol, Solo cv and nice fruits belonging to Guinea Gold and Sinta cv. As for the positive descriptors, "Peach Flavor" and "Taste of Exotic Fruit" there are no significant differences, the best cultivars are Honeydew, Cartagena 
and Solo. An evaluation of "Peel Color" and "Flesh Color" showed no significant differences between these values.

Comparing the results obtained in sensorial analysis with TSSC, it is noticeable that the panelists detected the differences found in soluble solid. In conclusion, we can say that the six different cultivars have received higher scores for the parameters related to flesh color, to sweetness, to juiciness, to peel color and to the sensations related to the odor of exotic fruits.

\section{Conclusions}

All cultivars analyzed reach chemical-physical traits that satisfy the market needs. However, our results showed a wide range of variability in terms of physicochemical traits, proximal composition, antioxidant capacity, and sensory characteristics. In fact, significant differences were found in the characteristics in a genotype-dependent manner. As for sensory analysis, the descriptors related to unpleasant defects or sensations always have very low scores. Moreover, the fruits of the six cultivars are rich in molecules with antioxidant activity, especially polyphenolic phytocomponents. These data suggest a potential protective effect to the quantities commonly consumed with food. In In conclusion, we can say that our data are comparable to the tropical and subtropical fruits; and highlight the possibility of obtaining quality papaya fruits in a Mediterranean climate harvesting fruit with more than $50 \%$ of yellow surface and using greenhouse growing. Further studies, which are not the subject of this research, should analyze the vegetative-productive characteristics of these genotypes in order to assess their overall potential.

Author Contributions: Conceptualization, V.F. and C.G.; methodology, V.F., C.G. and E.P.; formal analysis, I.T., A.P., G.S. and G.M.; investigation, I.T., A.P., G.M. and E.P.; data curation, G.S., I.T. and A.P.; writing —original draft preparation, A.P. and I.T.; writing-review and editing, V.F. and C.G; validation, V.F. and C.G.; supervision, V.F. and C.G. All authors have read and agreed to the published version of the manuscript.

Funding: This research received no external funding.

Acknowledgments: A special acknowledgement should be addressed to the organic farm "Orto di Nonno Nino" for the fruits used in this experiment.

Conflicts of Interest: The authors declare no conflict of interest.

\section{References}

1. Farina, V.; Passafiume, R.; Tinebra, I.; Scuderi, D.; Saletta, F.; Gugliuzza, G.; Sortino, G. Postharvest Application of Aloe vera Gel-Based Edible Coating to Improve the Quality and Storage Stability of Fresh-Cut Papaya. J. Food Qual. 2020, 2020, 1-10. [CrossRef]

2. Evans, E.A.; Ballen, F.H.; Crane, J.H. Cost Estimates of Establishing and Producing Papaya (Carica papaya) in South Florida1. EDIS 2012, FE918.

3. Sharma, S.K.; Mitra, S.K.; Saran, S. Papaya production in India - history, present status and future prospects. Acta Hortic. 2016, 1111, 87-94. [CrossRef]

4. Cabrera, J.A.; Lobo, M.G.; Ritter, A.; Raya, V.; Pérez, E. Characterization of ambient conditions inside greenhouses of papaya (Carica papaya L.) crops in the Canary Islands. Acta Hortic. 2019, 1250, 145-152. [CrossRef]

5. Calabrese, F. Frutticoltura Tropicale e Subtropicale II Fruttiferi Legnosi; Edagricole: Italia, Bologna, 1993.

6. Karunamoorthi, K.; Kim, H.M.; Jegajeevanram, K.; Xavier, J.; Vijayalakshmi, J. Papaya: A gifted nutraceutical plant-a critical review of recent human health research. Tang Humanit. Med. 2014, 4, 2.1-2.17. [CrossRef]

7. Marelli de Souza, L.; Silva Ferreira, K.; Paes Chaves, J.B.; Lopes Teixeira, S. L-ascorbic acid, $\beta$ - Carotene and lycopene content in papaya fruits (Carica papaya L.) without physiological skin freckles. Sci. Agric. 2008, 65, 246-250. [CrossRef]

8. Basulto, F.S.; Duch, E.S.; Espadas, F.; Plaza, R.D.; Saavedra, A.L.; Santamaría, J.M. Postharvest ripening and maturity indices for Maradol papaya. Interciencia 2009, 34, 583-588. 
9. Schweiggert, R.M.; Steingass, C.B.; Mora, E.; Esquivel, P.; Carle, R. Carotenogenesis and physico-chemical characteristics during maturation of red-fleshed papaya fruit (Carica papaya L.). Food Res. Int. 2011, 44, 1373-1380. [CrossRef]

10. Fuggate, P.; Wongs-Aree, C.; Noichinda, S.; Kanlayanarat, S. Quality and volatile attributes of attached and detached "Pluk Mai Lie" papaya during fruit ripening. Sci. Hortic.-Amsterdam. 2010, 126, 120-129. [CrossRef]

11. Paull, R.E. Effect of temperature and relative humidity on fresh commodity quality. Postharvest Biol. Technol. 1999, 15, 263-277. [CrossRef]

12. Sharma, M.; Sitbon, C.; Subramanian, J.; Paliyath, G. Changes in nutritional quality of fruits and vegetables during storage. In Postharvest Biology and Technology of Fruits, Vegetables, and Flowers, 2nd ed.; John Wiley \& Sons: Hoboken, NJ, USA, 2008; pp. 443-466.

13. CBI Ministry of Foreign Affairs. Exporting Fresh Papayas to Europe. 2018. Available online: https: //www.cbi.eu/market-information/fresh-fruit-vegetables/papayas/ (accessed on 5 February 2020).

14. Gomez, M.; Lajolo, F.; Cordenunsi, B. Evolution of soluble sugars during ripening of papaya fruit and its relation to sweet taste. J. Food Sci. 2002, 67, 442-447. [CrossRef]

15. Miller, N.J.; Rice-Evans, C.A. Spectrophotometric determination of antioxidant activity. Redox. Rep. 1996, 2, 161-171. [CrossRef] [PubMed]

16. Wolfe, K.L.; Liu, R.H. Cellular antioxidant activity (CAA) assay for assessing antioxidants, foods, and dietary supplements. J. Agric. Food Chem. 2007, 55, 8896-8907. [CrossRef]

17. Gentile, C.; Di Gregorio, E.; Di Stefano, V.; Mannino, G.; Perrone, A.; Avellone, G.; Farina, V. Food quality and nutraceutical value of nine cultivars of mango (Mangifera indica L.) fruits grown in Mediterranean subtropical environment. Food Chem. 2019, 277, 471-479. [CrossRef] [PubMed]

18. Niki, E.; Packer, L.; Glazer, A.N. Free Radical Initiators as Source of Water- or Lipid-Soluble Peroxyl Radicals, Oxygen Radicals in Biological Systems Part. B: Oxygen Radicals and Antioxidants. Methods in Enzymology; Academic Press: Cambridge, MA, USA, 1990. [CrossRef]

19. Barros, L.; Baptista, P.; Ferreira, I.C.F.R. Effect of Lactarius piperatus fruiting body maturity stage on antioxidant activity measured by several biochemical assays. Food Chem. Toxicol. 2007, 45, 1731-1737. [CrossRef] [PubMed]

20. Kavanagh, F. Official Methods of Analysis of the AOAC, 13th ed.; Horwitz, W., Ed.; The Association of Official Analytical Chemists: Arlington, AV, USA, 1981; p. 1038.

21. Palazzolo, E.; Letizia Gargano, M.; Venturella, G. The nutritional composition of selected wild edible mushrooms from Sicily (southern Italy). Int. J. Food Sci. Nutr. 2011, 63, 79-83. [CrossRef] [PubMed]

22. Morand, P.; Gullo, J.L. Mineralization of plant tissues for the quantitative analysis of phosphorus, calcium, magnesium, sodium, potassium. Ann. Agronom. 1970, 21, 229-236.

23. Farina, V.; Gianguzzi, G.; Mazzaglia, A. Fruit Quality Traits of Six Ancient Apple (Malus domestica Borkh) Cultivars Grown in the Mediterranean Area. Int. J. Fruit Sci. 2015, 16, 275-283. [CrossRef]

24. Farina, V.; Gianguzzi, G.; Mazzaglia, A. Fruit quality evaluation of affirmed and local loquat (Eriobotrya japonica Lindl) cultivars using instrumental and sensory analyses. Fruits 2016, 71, 105-113. [CrossRef]

25. Farina, V.; Volpe, G.; Mazzaglia, A.; Lanza, C.M. Fruit quality traits of two apricot cultivars. Acta Hortic. 2010, 862, 593-598. [CrossRef]

26. Zaman, W.; Biswas, S.K.; Helali, M.O.H.; Ibrahim, M.; Hassan, P. Physicochemical composition of four papaya varieties grown at Rajshahi. J. Biosci. 1970, 14, 83-86. [CrossRef]

27. Codex Stan 183-1993, Standard for Papaya, FAO Revised 2001. Amended 2005. 2011. Available online: http: //www.fao.org/fao-who-codexalimentarius/sh-proxy/en/?lnk=1\&url=https\%253A\%252F\%252Fworkspace. fao.org\%252Fsites\%252Fcodex\%252FStandards\%252FCXS\%2B183-1993\%252FCXS_183e.pdf (accessed on 5 February 2020).

28. Blankenship, S.M.; Unrath, C.R. Ethylene inhibitor, 1-methylcyclopropene, delays apple softening. Hortscience 1998, 33, 469. [CrossRef]

29. Flores, F.; Ben Amor, M.; Jones, B.; Pech, J.C.; Bouzayen, M.; Latché, A.; Romojaro, F. The use of ethylene-suppressed lines to assess differential sensitivity to ethylene of the various ripening pathways in Cantaloupe melons. Acta Hortic. 2001, 553, 151-154. [CrossRef]

30. Jeong, J.; Huber, D.J.; Sargent, S.A. Influence of 1-methylcyclopropene (1-MCP) on ripening and cell-wall matrix polysaccharides of avocado (Persea americana) fruit. Postharvest Biol. Techn. 2002, 25, 241-256. [CrossRef] 
31. Bron, I.U.; Jacomino, A.P. Ripening and quality of 'Golden' papaya fruit harvested at different maturity stages. Braz. J. Plant. Physiol. 2006, 18, 389-396. [CrossRef]

32. Harker, F.R.; Lau, K.; Gunson, F.A. Juiciness of fresh fruit: A time-intensity study. Postharvest Biol. Technol. 2003, 29, 55-60. [CrossRef]

33. Campbell, O.E.; Merwin, I.A.; Padilla-Zakour, O.I. Characterization and the effect of maturity at harvest on the phenolic and carotenoid content of Northeast USA Apricot (Prunus armeniaca) varieties. J. Agric. Food Chem. 2013, 61, 12700-12710. [CrossRef]

34. Blasco, J.; Aleixos, N.; Cubero, S.; Lorente, D. Fruit, vegetable and nut quality evaluation and control using computer vision. In Computer Vision Technology in the Food and Beverage Industries; Woodhead Publishing: Cambridge, UK, 2012; pp. 379-399. [CrossRef]

35. Gayosso-García Sancho, L.E.; Yahia, E.M.; González-Aguilar, G.A. Identification and quantification of phenols, carotenoids, and vitamin C from papaya (Carica papaya L., cv. Maradol) fruit determined by HPLC-DAD-MS/MS-ESI. Food Res. Int. 2011, 44, 1284-1291. [CrossRef]

36. Barragán-Iglesias, J.; Méndez-Lagunas, L.L.; Rodríguez-Ramírez, J. Ripeness indexes and physico-chemical changes of papaya (Carica papaya L. cv. Maradol) during ripening on-tree. Sci. Hortic.-Amsterdam. 2018, 236, 272-278. [CrossRef]

37. Vázquez, G.E.; Ariza, F.R. Características de Calidad en Postcosecha de Papaya "Maradol" en la regiòn de las Huastecas; $1^{a}$ Reunión Nacional de Innovación Agrícola y Forestal: Merida, Mexico, 2006.

38. Zhou, L.; Paull, R.E. Sucrose metabolism during papaya (Carica papaya) fruit growth and ripening. J. Am. Soc. Hortic. Sci. 2001, 126, 351-357. [CrossRef]

39. Lobo, M.G.; Ozadali, F. Papaya. Tropical and Subtropical Fruits: Postharvest Physiology, Processing and Packaging, 1st ed.; Muhammad Siddiq-Wiley: Hoboken, NJ, USA, 2012; pp. 299-319.

40. Luthfunesa, B.; Hassan, P.; Absar, N.; Haque, M.E.; Khuda, M.E.; Pervin, M.M.; Shahanaz, K.; Hossain, M.I. Nutritional analysis of two Local varieties of Papaya (Carica papaya L.) at different maturation stages. Pak. J. Biol. Sci. 2006, 9, 137-140. [CrossRef]

41. Lazan, H.; Ali, Z.M.; Liang, K.M.; Yee, K.L. Polygalacturonase activity and variation in ripening of papaya fruit with tissue depth and heat treatment. Physiol. Plantarum. 1989, 77, 93-98. [CrossRef]

42. Al-Duais, M.; Hohbein, J.; Werner, S.; Böhm, V.; Jetschke, G. Contents of Vitamin C, Carotenoids, Tocopherols, and Tocotrienols in the Subtropical Plant Species Cyphostemma digitatumas Affected by Processing. J. Agric. Food Chem. 2009, 57, 5420-5427. [CrossRef]

43. Yuan, J.M.; Stram, D.O.; Arakawa, K.; Lee, H.; Yu, M.C. Dietary cryptoxanthin and reduced risk of lung cancer: The singapore Chinese Health Study. Cancer Epidem. Biomar. 2003, 12, 890-898.

44. Septembre-Malaterre, A.; Stanislas, G.; Douraguia, E.; Gonthier, M.P. Evaluation of nutritional and antioxidant properties of the tropical fruits banana, litchi, mango, papaya, passion fruit and pineapple cultivated in Réunion French Island. Food Chem. 2016, 212, 225-233. [CrossRef]

45. Vijaya Kumar Reddy, C.; Sreeramulu, D.; Raghunath, M. Antioxidant activity of fresh and dry fruits commonly consumed in India. Food Res. Int. 2010, 43, 285-288. [CrossRef]

46. Oufedjikh, H.; Mahrouz, M.; Amiot, M.J.; Lacroix, M. Effect of gamma-irradiation on phenolic compounds and phenylalanine ammonialyase activity during storage in relation to peel injury from peel of Citrus clementina Hort. ex. Tanaka. J. Agric. Food Chem. 2000, 48, 559-565. [CrossRef]

47. Gentile, C.; Reig, C.; Corona, O.; Todaro, A.; Mazzaglia, A.; Perrone, A.; Gianguzzi, G.; Agusti, M.; Farina, V. Pomological Traits, Sensory Profile and Nutraceutical Properties of Nine Cultivars of Loquat (Eriobotrya japonica Lindl.) Fruits Grown in Mediterranean Area. Plant. Food Hum. Nutr. 2016, 7, 330-338. [CrossRef]

48. Gupta, C.; Prakash, D. Phytonutrients as therapeutic agents. JCIM 2014, 11, 151-169. [CrossRef]

49. Noy, N. Vitamin A in regulation of insulin responsiveness: Mini review. Proc. Nutr. Soc. 2016, 75, $212-215$. [CrossRef]

50. Hammerling, U. Retinol as electron carrier in redox signaling, a new frontier in vitamin A research. Hepatobiliary Surg. Nutr. 2016, 5, 15. [PubMed]

51. Acin-Perez, R.; Hoyos, B.; Zhao, F.; Vinogradov, V.; Fischman, D.A.; Harris, R.A. Control of oxidative phosphorylation by vitamin A illuminates a fundamental role in mitochondrial energy homoeostasis. Faseb. J. 2010, 24, 627-636. [CrossRef] [PubMed] 
52. Wall, M.M. Ascorbic acid, vitamin A, and mineral composition of banana (Musa sp.) and papaya (Carica papaya) cultivars grown in Hawaii. J. Food Compos. Anal. 2006, 19, 434-445. [CrossRef]

53. U.S. Department Of Agriculture, Agriculture Research Service. Available online: https://fdc.nal.usda.gov/ fdc-app.html\#/food-details/341582/nutrients (accessed on 5 February 2020).

54. Garcia-Diaz, D.F.; Campion, J.; Arellano, A.V.; Milagro, F.I.; Moreno-Aliaga, M.J.; Martinez, J.A. Fat intake leads to differential response of rat adipocytes to glucose, insulin and ascorbic acid. Exp. Biol. Med. 2012, 237, 407-416. [CrossRef]

55. Akaniwor, J.O.; Arachie, S.N. Nutritive values of fruits and seeds usually eaten raw in Nigeria. J. Appl. Sci. Environ. Manag. 2002, 6,77-78. [CrossRef]

56. Hajare, S.N.; Saxena, S.; Kumar, S.; Wadhawan, S.; More, V.; Mishra, B.B.; Sharma, A. Quality profile of litchi (Litchi chinensis) cultivars from India and effect of radiation processing. Radiat. Phys. Chem. 2010, 79, 994-1004. [CrossRef]

57. Oloyede, O.I. Chemical Profile of Unripe Pulp of Carica papaya. Pak. J. Nutr. 2005, 4, 379-381. [CrossRef]

58. Cabral, T.A.; de Morais Cardoso, L.; Pinheiro-Sant'Ana, H.M. Chemical composition, vitamins and minerals of a new cultivar of lychee (Litchi chinensis cv. Tailandes) grown in Brazil. Fruits 2014, 69, 425-434. [CrossRef]

59. Kar, A.; Choudhary, B.K.; Bandyopadhyay, N.G. Preliminary studies on the inorganic constituents of some indigenous hypoglycaemic herbs on oral glucose tolerance test. J. Ethnopharmacol. 1999, 64, 179-184. [CrossRef]

(C) 2020 by the authors. Licensee MDPI, Basel, Switzerland. This article is an open access article distributed under the terms and conditions of the Creative Commons Attribution (CC BY) license (http://creativecommons.org/licenses/by/4.0/). 